\title{
PROJETO DE FUTURO NA DIMENSÃO SÓCIO AFETIVA: COMO SE CONSTROEM AS PERCEPÇÕES DE ALUNOS/AS DO ENSINO SECUNDÁRIO EM PORTUGAL E DO ENSINO MÉDIO NO BRASIL
}

\author{
Marilia Frassetto de Araujo ${ }^{1}$ \\ Célia Regina Rossi ${ }^{2}$ \\ Maria Filomena RodriguesTeixeira ${ }^{3}$ \\ Pala Regina Costa Ribeiro ${ }^{4}$
}

\section{Resumo}

A pesquisa buscou compreender o projeto de futuro na dimensão sócio afetiva por alunos/as do Ensino Médio em Portugal e no Brasil. A base teórica se deu através dos conceitos de cultura e adolescência como construções culturais e entende o projeto de futuro na referida dimensão como a definição dos afetos e paixões. Através de grupo focal com os/as adolescentes foi possível analisar suas narrativas sobre o tema, conhecer e analisar os discursos produzidos por eles/as sobre assuntos relacionados a sexualidade, gênero e diversidade sexual. A pesquisa verificou que a maioria dos/as adolescentes refletiam sobre seus projetos de futuro na dimensão sócio afetiva e apontou as diferenças que permeiam os comportamentos dos garotos e das garotas. É essencial problematizar esses assuntos de maneira ética e permitir que o/a adolescente reflita sobre seus relacionamentos entre pares, com a família, na comunidade, com responsabilidade e criticidade. A educação escolar é parte central neste processo.

\footnotetext{
${ }^{1}$ Pedagoga, Mestre, Faculdade de Ciências e Letras de Araraquara, UNESP. Endereço: Av. Antônia Pizinato Sturion, 516, CEP:13420-640 Piracicaba - SP, Brasil. Endereço eletrônico: marília.frassetto@ gmail.com

${ }^{2}$ Professora Doutora, Pós Doutora, Departamento de Educação, Instituto de Biociências, UNESP. Endereço: Av. 24 A, 1515, CEP: 13506-900 Rio Claro, SP, Brasil. Endereço eletrônico: celiarr@ rc.unesp.br

${ }^{3}$ Professora Doutora, Pós Doutora, Escola Superior de Educação - Instituto Politécnico de Coimbra. Endereço: Solum 3030-329, Coimbra, Portugal. Endereço eletrônico: filomenatx@gmail.com

${ }^{4}$ Professora Doutora, Pós Doutora, Universidade Federal do Rio Grande - FURG - Instituto de Educação, Endereço: Km 8 - Av. Itália - Carreiros, Rio Grande - RS, Brasil. 96203-900. Endereço eletrônico: pribeiro@vetorial.net
} 
Palavras-Chave: Projeto de Futuro; Adolescentes; Sexualidade; Relações de Gênero; Diversidade Sexual

\section{INTRODUÇÃO}

Essa pesquisa foi financiada pela Fundação de Amparo à Pesquisa do Estado de São Paulo, processo 2014/02224-6, e buscou discutir os projetos de futuro na dimensão sócio afetiva que envolveram questões relacionadas ao corpo, à sexualidade, às relações de gênero e à diversidade sexual de adolescentes do ensino secundário, em Coimbra, Portugal, e do Ensino Médio, em Piracicaba, estado de São Paulo, no Brasil.

Nesse estudo foi imprescindível abordar a cultura, uma vez que ele se debruçou sobre duas culturas que são distintas, apesar de algumas similaridades. Uma da América do Sul Brasil e outra da Europa - Portugal. A cultura, segundo Hall (1997), é constituída das formas de viver, de compreender e de explicar o mundo através do ser humano. $\mathrm{O}$ autor explica sobre os significados e os códigos que os seres humanos utilizam para organizar e regular suas condutas em relação aos outros.

Estes sistemas ou códigos de significados dão sentido às nossas ações. Eles nos permitem interpretar significativamente as ações alheias. Tomados em seu conjunto, eles constituem nossas "culturas". Contribuem para assegurar que toda ação social é "cultural", que todas as práticas sociais expressam ou comunicam um significado e, neste sentido, são práticas de significação. (HALL 1997, p. 1)

Raquel Quadrado (2006) afirma que

a cultura é constituída por uma rede de representações que fazem parte do modo de vida de cada grupo social, definindo como esses grupos devem ser. A cultura é, ao mesmo tempo, determinada por essas instâncias sociais e determinante delas. Esse campo cultural é marcado por relações de poder, pois é nele e através dele que os significados são definidos, marcados e fixados, num jogo através do qual cada grupo tenta impor os seus significados sociais aos demais grupos. As práticas sociais são, então, práticas culturais, práticas de significação. (p. 24)

As práticas culturais são produtoras de significados e, dessa forma, têm o objetivo de desconstruir os binarismos e as discriminações existentes entre cultura acadêmica e cultura popular ou entre alta e baixa cultura. (QUADRADO, 2006) 
O conceito da adolescência, então, foi uma construção sócio-histórica, emergida a partir da cultura desde o seu cunho biológico até as diferenças colocadas através dos sistemas de representação.

O período nem sempre existiu como uma fase específica do desenvolvimento, que necessitava de uma atenção especial devido a construção da identidade, reconhecia-se apenas a puberdade (AVILA, 2005).

A identidade é fragmentada, plural, construída ao longo das trajetórias percorridas, podendo ou não ser antagônicas, e está sempre em processo de mudança e transformação (HALL 2014).

As identidades são construídas através da diferença e são relacionais, ou seja, dependem de outro para existir. Apesar de serem construídas na diferença, não são fixas, são passíveis de mudanças. A diferença é definida por uma marcação simbólica em relação a outras identidades e define quem está incluído e quem está excluído. (WOODWARD, 2014; HALL, 2014).

Woodward (2014) afirma que as pessoas "são diferentemente posicionadas pelas diferentes expectativas e restrições sociais envolvidas em cada uma dessas diferentes situações, representando-nos, diante dos outros, de forma diferente em cada um desses contextos" (p. 31).

Afim de delimitar as questões abordadas nos instrumentos utilizados para a produção de dados, adotou-se, nessa pesquisa, a perspectiva de Projeto de Futuro de Marcelino, Catão e Lima (2009)

\begin{abstract}
Como perspectiva de futuro, o projeto é vivenciado desde a infância, quando o indivíduo experiência sua condição social por meio da família, da comunidade e mais tarde, na instituição escolar. Entretanto, essa construção não se restringe somente às condições objetivas de vida, mas sim pelas características da dialética entre a subjetividade e a objetividade, pois é através da reflexão crítica de suas vivências que os indivíduos veem o que é possível ou não, para uma determinada realidade no futuro. "A construção do projeto de vida é uma configuração humana do ser cidadão, sujeito de sua história individual/social, uma criação analítica, crítica e articulada." (p. 547)
\end{abstract}

A definição do projeto de futuro na dimensão sócio afetiva,

é caracterizada pela definição dos afetos, das paixões, da ética, pela mediação entre o sofrimento e a felicidade, entre o prazer, ausência do prazer e o desprazer, pela potência da ação humana (Espinosa, 2005) não como propriedade do sujeito, mas como possibilidade do vir a ser, enquanto capacidade de ser afetado pelo outro, num processo de possibilidades infinita de criação e de entrelaçamentos. Estudar o ser humano, sua vida e concepções de projeto de vida, é analisar a ética e a afetividade, 
PROJETO DE FUTURO NA DIMENSÃO SÓCIO AFETIVA: COMO SE CONSTROEM AS PERCEPÇÕES DE ALUNOS/AS DO ENSINO SECUNDÁRIO EM PORTUGAL E DO ENSINO MÉDIO NO BRASIL

como questões de sobrevivência, é ampliar as concepções de projeto de vida para além das necessidades e carência material [...] (MARCELINO et. al. 2009 p.547).

O projeto de futuro na dimensão sócio afetiva envolve questões relacionadas à sexualidade, ao corpo, às diferenças de gênero e à diversidade sexual.

Entrelaçando projeto de futuro, sexualidade e espaço escolar, Magalhães e Silva (2013) consideram que a escola, além de ser responsável pela apropriação e reconstrução de novos conhecimentos, é o local principal na produção das identidades, na "fabricação dos sujeitos".

Debora Britzman (2001) afirma que a cultura da escola permite que o ensino seja mais importante do que o entendimento de questões íntimas e que, nessa cultura, as possibilidades de novas questões e desenvolvimento da curiosidade não acontecem, o que faz o campo da sexualidade ser deixado para segundo plano, um espaço de respostas certas ou erradas.

Amaral, Domingues e Silva (2013) afirmam ainda que é na escola que os/as alunos/as têm a oportunidade de vivenciar e trocar experiências e que as necessidades deles/as, por mais que sejam reprimidas, vão surgir e se sobrepor às normas. Partindo dessa premissa, pode-se entender que as questões relacionadas ao projeto de futuro na dimensão sócio afetiva são relegados e tidos como um assunto menor ou sem importância nas instituições escolares em geral.

Segundo Louro (1999) a sexualidade é construída, ao longo de toda a vida, de diversos modos, por todos os sujeitos.

A sexualidade envolve rituais, linguagens, fantasias, representações, símbolos, convenções... Processos profundamente culturais e plurais. (...) As possibilidades da sexualidade - das formas de expressar os desejos e prazeres - também são sempre socialmente estabelecidas e codificadas.

Para Britzman (1996), a sexualidade é como um viver apaixonado, uma paixão entre pessoas e tem relação com a liberdade e com o direito de construir uma sociedade relevante, interessante e vital. Além disso, segundo a autora, a sexualidade desencadeia o desejo de aprender, a curiosidade e o ato de tornar-se um cidadão ou cidadã. Entretanto, na escola,

quando chega a ser tratado, o conhecimento de sala de aula sobre sexualidade é tipicamente sinônimo de reprodução heterossexual, embora até mesmo esse conhecimento seja banalizado. Além disso, a assim chamada informação técnica sobre reprodução sexual é altamente contestada porque a informação sobre sexo é vista como a causa da atividade sexual (BRITZMAN, 1996, p. 78) 
Sobre as relações de gênero, é necessário considerar as maneiras como o gênero é representado, pois essas representações podem estabelecer diferenças e identidades que colocam cada sujeito em uma determinada classificação.

Para Joan Scott (1990) o gênero é uma categoria útil à história da sociedade e não apenas à história das mulheres. A autora (1990) propõe um uso do gênero muito mais abrangente, afirmando que o gênero é um elemento constitutivo de relações sociais baseado nas diferenças percebidas entre os sexos, e que, além disso, é uma forma primeira de significar as relações de poder. Portanto, o termo gênero alude os processos culturais que agem por intermédio das relações de poder, construindo padrões hegemônicos, a partir de corpos sexuados.

É possível compreender a identidade de gênero como a auto percepção de cada indivíduo em relação às categorias sociais que se referem ao masculino e ao feminino e a uma representação biológica, construída por fatores sociais e culturais que são predominantes na formação humana. O desenvolvimento da identidade ocorre desde o nascimento, em uma constante troca entre o sujeito e os outros, de maneira móvel e mutável. (LOURO, 2003; RIBEIRO, 2002).

Meyer (2003) aponta que os gêneros são como "produtos" criados a partir do âmbito social, cultural, histórico e linguístico, que decorre das relações de poder, compreendendo os processos que produzem e afastam os corpos dotados de sexo, gênero e sexualidade. Já Ribeiro e Soares (2013) sintetizam que o conceito de gênero ocorre a partir de construções culturais, produzidas historicamente com princípio nas características de natureza biológica dos corpos. Além disso, as autoras (2013) ressaltam que,

\footnotetext{
os gêneros se fazem e se refazem, continuamente, ao longo de sua existência. (...) Há uma multiplicidade de construções do ser masculino e do ser feminino, pois diversificados modelos ideais, padrões e imagens, de diferentes contextos (classes, raças, etnias, nacionalidade, religião) configuram o processo de formação do homem e da mulher. (p. 26)
}

No ambiente escolar, segundo Ribeiro e Soares (2013), algumas situações como filas, grupos de trabalho, atividades físicas e brincadeiras são separados por sexo, considerados como "de menino" ou "de menina", o que reforça essa distinção social.

Sobre as relações de gênero no espaço escolar, o assunto também é de pouca relevância entre os/as professore/as. O olhar dos/as funcionários/as (direção, professores/as, coordenação, e os/as demais) não é sensível para essa temática no cotidiano escolar, isso se dá 
PROJETO DE FUTURO NA DIMENSÃO SÓCIO AFETIVA: COMO SE CONSTROEM AS PERCEPÇÕES DE ALUNOS/AS DO ENSINO SECUNDÁRIO EM PORTUGAL E DO ENSINO MÉDIO NO BRASIL

talvez pela dificuldade de refletir e problematizar, além das desigualdades entre os sexos, mas também os significados de gênero implícito a essas desigualdades e pouco considerados pelas políticas públicas que regem o sistema educacional (VIANNA E UNBEHAUM, 2004).

A instituição escolar também é um dos locais em que é necessário problematizar a diversidade sexual. Segundo Dinis (2011) a homofobia, ainda é um preconceito tolerado, que se constitui como uma maneira de afirmação e de constituição da heterossexualidade. $\mathrm{Na}$ escola a homofobia ocorre através de agressões verbais e/ou físicas aos/às estudantes que não se adéquam a heteronormatividade.

Nesse sentido, se faz de suma importância, que a escola trabalhe com "educação na diversidade, para a diversidade e pela diversidade" que segundo Junqueira (2013) abordam a convivência social, cidadã e democrática, além de promoverem a igualdade, a inclusão e a integração social. A “educação na diversidade" propõe a inclusão do "outro". A "educação pela diversidade" visa o reconhecimento e a legitimação da diferença. A "educação pela diversidade" atua na perspectiva do convívio entre pessoas diferentes.

\section{ABORDAGEM METODOLÓGICA}

A produção de dados aconteceu através da observação - por meio da presença da pesquisadora nas escolas - e da realização do grupo focal com os/as adolescentes.

Segundo Gatti (2005) a realização de grupos focais é uma estratégia que proporciona "o conhecimento das representações, percepções, crenças, hábitos, valores, restrições, preconceitos, linguagens e simbologias prevalentes no trato de uma dada questão por pessoas que partilham alguns traços em comum" (p. 11).

Para atingir os objetivos propostos no projeto de pesquisa, o grupo focal foi minuciosamente elaborado. As situações-problema foram criadas em formato de narrações de vivências cotidianas de adolescentes e tiveram como objetivo geral envolver os/as alunos/as nas discussões, fazer com que se colocassem nas situações iniciais narradas e emitissem as suas opiniões sobre determinados assuntos.

Segundo Larrosa (2002, p. 70),

É no trato com os textos que estão já aí que se adquire o conjunto dos procedimentos discursivos com os quais os indivíduos se narram a si mesmo [...] A consciência de si própria não é algo que a pessoa progressivamente descobre e aprende a descrever 
ARAUJO, M. F.; ROSSI, C. R.; TEIXEIRA, M. F. R.; RIBEIRO, P. R. C.

melhor. É, antes, algo que se vai fabricando e inventando, algo que vai se construindo e reconstruindo em operações de narração e com a narração.

As situações, como serão demonstradas a seguir, foram apresentadas por meio de pequenos textos narrativos, de no máximo 5 linhas, deixados em aberto, sempre com reticências para que os/as adolescentes refletissem e elaborassem o final, tomando as decisões e se posicionando da maneira como desejassem.

Cunha (1997) afirma que

quando uma pessoa relata os fatos vividos por ela mesma, percebe-se que reconstrói a trajetória percorrida dando-lhe novos significados. Assim, a narrativa não é a verdade literal dos fatos, mas, antes, é a representação que deles faz o sujeito e, dessa forma, pode ser transformadora da própria realidade. (p. 187)

\section{Situação-Problema 1}

Lívia tem 16 anos e tem um irmão gêmeo, o Leonardo. O Pai comprou preservativos só para o Leonardo. Lívia questionou-se sobre a atitude do pai e confessou à sua amiga, "Ora, por que é que só os meninos podem andar com preservativos? Uma menina não pode ter alguns em sua bolsa? Por que é que algumas coisas valem para os meninos e não para as meninas?”. A amiga disse...

\section{Situação-Problema 2}

No banheiro da escola, a funcionária me viu beijando um menino e fez um enorme escândalo gritando "Só me faltava isto! Dois meninos se beijando!!". Imediatamente nos levou à Direção, onde estamos aguardando a Diretora. O que nos acontecerá? Seremos expulsos? A Diretora contará aos nossos pais? Como será que os/as nossos/as colegas reagirão ao saber disso? Por que é que um menino e uma menina podem se beijar e dois meninos não podem? A diretora nos chamou e disse...

\section{Situação-Problema 3}

Brasil: O Felipe está muito apaixonado pela Bia, ela é alta, cabelos compridos, e ele a acha linda. Ele é gordo, usa óculos e aparelho nos dentes, mas é muito inteligente e legal. Será que ele tem alguma chance com ela? Ele bem tenta impressioná-la com os seus conhecimentos sobre tecnologia. Deseja muito conquistá-la. Encheu-se de coragem e foi falar com ela... 
PROJETO DE FUTURO NA DIMENSÃO SÓCIO AFETIVA: COMO SE CONSTROEM AS PERCEPÇÕES DE ALUNOS/AS DO ENSINO SECUNDÁRIO EM PORTUGAL E DO ENSINO MÉDIO NO BRASIL

Situação-Problema 4

Brasil:Hoje descobri que a menina que senta ao meu lado na carteira é lésbica. Fiquei assustada, não sei o que fazer, será que mudo de lugar? Será que peço para mudar de sala? Será que espalho a todos/as os/as nossos/as colegas para que ela se intimide e tome alguma atitude, como, por exemplo, sair da escola? Fui falar com o coordenador...

Situação-Problema 5

Brasil: Não vejo a hora de acabar o $3^{\circ}$ ano do Ensino Médio para finalmente me casar... Já encontrei o amor da minha vida. É uma pena que ninguém aqui da escola me entenda ou me apoie. Vou...

Através dessas situações, a pesquisadora conseguiu realizar o grupo focal e desencadear discussões. Durante os grupos focais foi possível perceber que em alguns momentos emitiam sua opinião e em outros momentos assumiam o papel da personagem.

Assim, a narrativa como investigação foi uma estratégia porque, segundo Longaray (2010), somos seres contadores de histórias e, na ação de narrar histórias, os sujeitos constituem sua própria identidade, adotando diversas posições de sujeito, uma vez que elas são produzidas em diferentes contextos sociais.

A análise de conteúdo foi à metodologia utilizada para analisar os dados produzidos pelos grupos focais. Segundo Caregnato e Mutti (2006), a análise de conteúdo é uma técnica de pesquisa que trabalha com a palavra, possibilitando de forma objetiva e prática produzir inferências do conteúdo da comunicação de um texto replicável ao seu contexto social.

\section{RESULTADOS E DISCUSSÃO}

Através das falas dos/as participantes do grupo focal foi possível extrair as seguintes categorias e subcategorias:

Sexualidade- Relacionamentos Amorosos

Relações de Gênero - Meninos e Meninas e Relações de Poder

Diversidade Sexual - Homossexualidade e Homofobia.

Sexualidade -Relacionamentos Amorosos 
ARAUJO, M. F.; ROSSI, C. R.; TEIXEIRA, M. F. R.; RIBEIRO, P. R. C.

\begin{tabular}{|c|c|}
\hline \multicolumn{2}{|l|}{ Relacionamentos Amorosos } \\
\hline Adolescente Portugal & Adolescente Brasil \\
\hline $\begin{array}{l}\text { "Podem perceber que não é a melhor } \\
\text { escolha que fizeram (o casamento)... } \\
\text { Eles não vivem os momentos de escola } \\
\text { né, que todas as pessoas deviam viver..." }\end{array}$ & $\begin{array}{l}\text { "Sei que é uma escolha precipitada, mas } \\
\text { eu o amo do mesmo jeito e sei que estou } \\
\text { fazendo a escolha certa. Caso eu me } \\
\text { arrependa vou continuar vivendo a } \\
\text { minha vida." }\end{array}$ \\
\hline
\end{tabular}

Através desses discursos fica explicito que o casamento é considerado um plano de futuro para os/as jovens.

Quando os mesmos jovens foram questionados de maneira direta ou indireta sobre o projeto de futuro na dimensão sócio afetiva, as respostas e colocações envolviam sempre o casamento heterossexual.

Apesar de o casamento ter sido o plano de futuro com maior evidência por eles/as, era um plano que não poderia ser realizado a qualquer momento, uma vez que eram necessárias algumas etapas para que ele se realizasse. Entre as etapas estavam terminar o ensino secundário, terminar a faculdade, ter um trabalho e estabilidade financeira.

Dessa forma, Justo (2005, p.75) afirma que,

Se por um lado é atraente o ideário do amor romântico, pela promessa de segurança, confiabilidade, fidelidade, durabilidade e outras vantagens, por outro, também é fascinante a promessa da maior independência, autonomia, realização, diversidade e outras coisas com as quais o amor confluente acena.

Bauman (1998), ao explicitar em seu texto a temática do namoro, enfatiza que ele está ligado à sexualidade. Segundo o autor (1998), antes a sexualidade era colocada a serviço de um projeto de vida ou de um relacionamento, ou seja, orientava-se para a consecução de outros objetivos além do próprio prazer sexual. Hoje, está desconectada de outras buscas, cumprindo uma finalidade hedonista.

Sendo assim, no quesito namoro, para os/as adolescentes participantes de Portugal, o namoro está atrelado ao casamento que deve acontecer após a estabilidade profissional e financeira. Já no Brasil, os/as adolescentes colocaram que se os pais do casal adolescente de namorados tiverem boas condições financeiras, não há mal nenhum em se casar, já que não passariam por necessidades financeira.

Entre os/as adolescentes dos dois países há uma diferença muito grande, no que tange a situação financeira e a independência financeira. Em Portugal, os/as adolescentes pensam na 
PROJETO DE FUTURO NA DIMENSÃO SÓCIO AFETIVA: COMO SE CONSTROEM AS PERCEPÇÕES DE ALUNOS/AS DO ENSINO SECUNDÁRIO EM PORTUGAL E DO ENSINO MÉDIO NO BRASIL

independência financeira e emocional, só com essa independência poderão pensar em um casamento, como uma nova vida a dois. No Brasil, os/as adolescentes pensam no casamento, sem a preocupação da independência financeira. Não há desvinculação de suas famílias, os discursos mostram que podem recorrer à família e que o casamento pode ser realizado atrelado a dependência financeira familiar.

A construção das relações amorosas para os/as adolescentes portugueses/as está pautada na citação de Justo (2005) no que tange ao ideário de amor romântico e da autonomia, demonstrando responsabilidade e planos mais elaborados para o futuro.

Já os/as adolescentes brasileiros/as permanecem entre os apontamentos de Justo (2005) e Bauman (1998), demonstrando confusão e insegurança quanto aos relacionamentos e a independência, presos ao suporte familiar.

\begin{tabular}{|c|c|}
\hline \multicolumn{2}{|c|}{ Relações de Gênero - Meninos e Meninas } \\
\hline Adolescentes Portugal & Adolescentes Brasil \\
\hline $\begin{array}{l}\text { "As meninas, levar um menino a casa, } \\
\text { não; o menino levar uma menina a casa, } \\
\text { já é diferente." }\end{array}$ & $\begin{array}{l}\text { "Os pais são mais liberais com os } \\
\text { meninos e não dão (preservativos) para } \\
\text { as meninas para não incentivar a fazer } \\
\text { (sexo) porque tem medo que elas fiquem } \\
\text { grávidas." }\end{array}$ \\
\hline $\begin{array}{l}\text { "Se os dois tem a mesma idade, por que } \\
\text { é que o rapaz pode ter relações e a } \\
\text { rapariga não pode?" }\end{array}$ & $\begin{array}{l}\text { "Normalmente quem usa a camisinha éo } \\
\text { homem, as mulheres usam o } \\
\text { anticoncepcional" }\end{array}$ \\
\hline $\begin{array}{l}\text { "A sociedade em que vivemos julga } \\
\text { muito mais facilmente uma rapariga por } \\
\text { práticas sexuais enquanto que para os } \\
\text { rapazes essa mesma prática é símbolo } \\
\text { de masculinidade e superioridade sendo } \\
\text { assim muito mais facilmente aceite." }\end{array}$ & $\begin{array}{l}\text { "Se a menina ficar com muitos meninos } \\
\text { ela é galinha, se o menino ficar com } \\
\text { muitas meninas é uma coisa boa" }\end{array}$ \\
\hline
\end{tabular}

As relações de gênero em seu sentido amplo estiveram fortemente presentes nos discursos e permearam todo o tempo esses discursos dos/as adolescentes na realização dos três grupos focais. 
Para Scott (1990), gênero é um elemento constitutivo das relações sociais fundadas sobre as diferenças percebidas entre os sexos e também um modo primordial de dar significado às relações de poder.

Louro (2008) e Silva e Magalhães (2013) trazem as questões culturais e as relações de gênero, assim como as temáticas vivenciadas e construídas pela adolescência, como uma construção social e cultural.

Silva (1999 p. 93), discorre que "o mundo social está feito de acordo com os interesses e as formas masculinas de pensamento e conhecimento". O autor afirma, assim, que a sociedade foi/está produzida, construída com as características do gênero dominante, no caso, o masculino.

Britzman (1996) aponta que a escola (funcionários/as e professores/as) controla constantemente a orientação sexual de seus/as alunos/as com a intenção de reforçar o comportamento heteronormativo. A instituição escolar, assim como outras instituições sociais, tenta adequar seu alunado ao gênero a que ele pertence de acordo com os aspectos biológicos.

Nas rodas de conversa com os/as adolescentes portugueses/as e brasileiros/as, eles/as apontaram fortemente a distinção entre masculino e feminino, marcando a sobreposição do masculino sobre o feminino; o masculino é superior, com mais direitos e mais liberdade. (SILVA, 1999). O gênero e a sexualidade são experimentados e aprendidos de maneira cultural e o que tem chegado a esses/as adolescentes, que atuaram na pesquisa, com seus discursos permeados de uma construção heteronormativa, foi que o sexo masculino é o dominante e o sexo feminino é o dominado (LOURO, 2008).

Essa cultura de gênero e de sexualidade que é vivenciada pelos/as adolescentes nas suas comunidades, nas suas famílias e nas escolas vem carregada de controle e reforço dentro de um modelo único, o da heteronormatividade, como afirma Britzman (1996). Assim, o sexo masculino é apontado como forte e racional e o sexo feminino como frágil, emotivo, que necessita de cuidados e apoio, fatores que levam as relações de poder e o poder do "sexo considerado forte" sobre o sexo considerado frágil.

Através dos discursos dos/as alunos/as pôde-se notar que alguns/as deles/as problematizaram sobre as diferenças de gênero e as desvantagens tem perante o homem, marcando as desigualdades entre homens e mulheres, ou seja, identificaram o binarismo masculino/feminino e o incômodo com estereótipos criados para homens e mulheres. 
PROJETO DE FUTURO NA DIMENSÃO SÓCIO AFETIVA: COMO SE CONSTROEM AS PERCEPÇÕES DE ALUNOS/AS DO ENSINO SECUNDÁRIO EM PORTUGAL E DO ENSINO MÉDIO NO BRASIL

\begin{tabular}{|c|c|}
\hline \multicolumn{2}{|l|}{ Relações de Gênero -Relações de Poder } \\
\hline Adolescentes Portugal & $\begin{array}{l}\text { No Brasil não emergiram falas } \\
\text { relacionadas a subcategoria "Relações de } \\
\text { Poder". }\end{array}$ \\
\hline $\begin{array}{l}\text { "(..) os nossos pais viveram numa época } \\
\text { em que a mulher era inferior ao homem. } \\
\text { Por isso têm uma mentalidade um pouco } \\
\text { retrógrada e tendência para proteger } \\
\text { mais o elemento feminino." }\end{array}$ & \\
\hline $\begin{array}{l}\text { "Socialmente, na geração dos nossos } \\
\text { pais, o homem era visto como um ser } \\
\text { mais forte e a mulher como um ser mais } \\
\text { frágil..." }\end{array}$ & \\
\hline $\begin{array}{l}\text { "Nós aprendemos a viver com esses } \\
\text { ideais (referentes a sociedade } \\
\text { machista) ... Que é mais aceitável para } \\
\text { ele (o rapaz) ter algumas ações do que } \\
\text { para a rapariga..." }\end{array}$ & \\
\hline
\end{tabular}

Louro (2008) afirma que a posição do homem branco heterossexual de classe média, construída historicamente, atua como uma identidade referência que é diferente de todas as identidades que não correspondam ou se afastem desta. Esta posição dita como normal é onipresente e invisível, sem qualquer necessidade de referi-la, serão apontadas as identidades diferentes dessa.

Dessa forma, entre inúmeras identidades existentes, uma delas é a posição da mulher, perceptível em alguns discursos dos/as adolescentes como sendo de uma posição inferior, de menos direitos. Foi possível identificar também referências como a do sexo feminino ser frágil ou com a necessidade de proteção por parte do sexo masculino, colocadas na subcategoria "relações de poder".

A partir dos trechos dos discursos apresentados pelos/as alunos/as portugueses/as, foi possível identificar, como afirma Louro (2008), resquícios de que "as mulheres se constituíam no "segundo sexo"' (p. 20), visto que nas falas desses/as, o homem é colocado como forte, sábio, detentor do conhecimento e da razão e protetor da mulher, uma vez que sabe o que é melhor para ela.

Através desses discursos, os/as adolescentes apontaram que a mídia (televisão, 
ARAUJO, M. F.; ROSSI, C. R.; TEIXEIRA, M. F. R.; RIBEIRO, P. R. C.

revistas, internet, redes sociais, filmes), as escolas, a comunidade, as famílias, constroem a mulher de maneira estereotipada, como sexo frágil, símbolo de delicadeza e pureza, com necessidade de proteção, cuidado e, portanto, sem liberdade.

própria visão de mundo, reforço que a compreensão cultural possibilita a expressão das diferenças, das peculiaridades; valoriza o indivíduo, enquanto sujeito de sua própria vivência; permite a contextualização desse indivíduo e promove um olhar dialético em relação ao nosso agir (RESSEL E GUALDA, 2003, p. 86).

Nessa perspectiva, a comunidade, a escola, a família, as diversas instituições são atravessadas pelo gênero e pelas relações de poder, na fala dos/as estudantes, que expressam e (re)significam essas representações transmitidas culturalmente de que o sexo masculino é mais forte e o sexo feminino é mais frágil.

No entanto, os/as adolescentes não são somente receptores da cultura imposta para eles/as, eles/as são receptores, mas reinterpretam e analisam as mensagens que recebem, e podem entende-las, critica-las e discordar das mesmas. Nos seus discursos foi possível identificar estranhamentos e questionamentos nessa relação de poder do homem sobre a mulher. O significado desse desconforto, desses questionamentos, é uma abertura, uma fissura, para uma nova possibilidade de aprendizagem por parte das instituições escolares, mas poucas aproveitam essas fissuras.

\begin{tabular}{|c|c|}
\hline \multicolumn{2}{|c|}{ Diversidade Sexual - Homossexualidade } \\
\hline Adolescentes Portugal & Adolescentes Brasil \\
\hline $\begin{array}{l}\text { "É igual, se um casal é heterossexual } \\
\text { pode ter uma relação mantida em } \\
\text { público, acho que um casal homossexual } \\
\text { também..." }\end{array}$ & $\begin{array}{l}\text { "Não se preocupem com o que as } \\
\text { pessoas vão pensar, pois se vocês se } \\
\text { amam, corram atrás do que traz } \\
\text { felicidade pra vocês." Referente a } \\
\text { situação-problema } 2\end{array}$ \\
\hline $\begin{array}{l}\text { "Devemos respeitar as orientações } \\
\text { sexuais de cada pessoa e aprender a } \\
\text { viver com as diferenças de cada um." }\end{array}$ & $\begin{array}{l}\text { "Essa menina poderá ser feliz e ter uma } \\
\text { família se ela quiser com a pessoa que } \\
\text { ela escolher para passar o resto de sua } \\
\text { vida." Referente a situação-problema } 4\end{array}$ \\
\hline
\end{tabular}

Alguns/as adolescentes de ambas as realidades trataram a homossexualidade de maneira natural. As falas se enquadram no que diz Silva (1999). "Deve-se tolerar e respeitar a diferença porque sob a aparente diferença há uma mesma humanidade” (p. 68). 
PROJETO DE FUTURO NA DIMENSÃO SÓCIO AFETIVA: COMO SE CONSTROEM AS PERCEPÇÕES DE ALUNOS/AS DO ENSINO SECUNDÁRIO EM PORTUGAL E DO ENSINO MÉDIO NO BRASIL

Tanto adolescentes portugueses/as como adolescentes brasileiros/as, reproduzem o discurso de igualdade, o que aponta para uma identificação e desejo - não tão elaborado - de construção de um espaço de formação de cidadania e de respeito aos direitos humanos dentro das cercanias da escola.

\begin{tabular}{|c|c|}
\hline \multicolumn{2}{|l|}{ Diversidade Sexual-Homofobia } \\
\hline Adolescentes Portugal & Adolescentes Brasil \\
\hline $\begin{array}{l}\text { "Não costuma acontecer isto em sítios } \\
\text { públicos... As pessoas têm medo das } \\
\text { reações das pessoas, é um bocado raro } \\
\text { acontecer isso" (Sobre verem casais de } \\
\text { homossexuais na escola ou em lugares } \\
\text { públicos) }\end{array}$ & $\begin{array}{l}\text { "vocês sabem que nos olhos dos outros } \\
\text { isso é contra a sociedade, mas deve se } \\
\text { evitar pelo bem de vocês mesmos, vocês } \\
\text { mesmos sabem as consequências e não } \\
\text { quero que vocês sofram bullyng." } \\
\text { Referente a situação-problema } 2 \text {. }\end{array}$ \\
\hline $\begin{array}{l}\text { "Por exemplo, uma pessoa... É normal } \\
\text { que comentem, pronto, } \hat{e} \text { uma coisa } \\
\text { estranha e não se vê isso todos os dias, } \\
\text { principalmente num sítio da escola, } \\
\text { mas..." (Sobre conversar com um } \\
\text { homossexual) }\end{array}$ & $\begin{array}{l}\text { "Ver um menino e uma menina se } \\
\text { beijando não é tão assustador como ver } \\
\text { menino com menino se beijando." }\end{array}$ \\
\hline
\end{tabular}

As problematizações trazidas pelos/as adolescentes, no que tange as pessoas homossexuais, apontam para que as demonstrações de afeto sempre devam ocorrer fora da escola. Eles/as apontam ainda que apesar da escola contemplar os namoros, as paqueras, na perspectiva heterossexual, eles/as não julgavam adequado relacionamentos homossexuais dentro do espaço escolar, por deixar marcas e traços de contrastes, o que demonstra que os/as adolescentes consideraram que a homossexualidade deveria ser vivenciada na esfera privada.

Dinis (2011) afirma que o argumento da privacidade da vida sexual pode ser exposto quando as identidades sexuais são dentro da norma, as que não são realmente faladas, que são reduzidas ao mundo da vida privada, são aquelas que divergem da norma heterossexual. $\mathrm{O}$ pressuposto da heterossexualidade se desvela explicitamente exposto nas aulas de Ciências que abordam a sexualidade, apenas pelo viés reprodutivo, pelos livros de literatura, que abordam apenas o amor romântico heterossexual, e também pelo modelo da família nuclear que é constantemente reproduzido nos livros didáticos. 
Deborah Britzman (1996) afirma que "a insistência de que a sexualidade deva ser confinada à esfera privada reduz a sexualidade às nossas específicas práticas sexuais individuais, impedindo que concebamos a sexualidade como sendo definida no espaço social mais amplo, através de categorias e fronteiras sociais" (1996, p. 80).

Nas escolas pesquisadas, os/as estudantes falaram que os/as jovens (eles/as mesmos/as) eram menos preconceituosos, ou "aceitavam mais" pessoas homossexuais. Sendo assim, foi possível identificar o preconceito que era sempre acompanhado de palavras que contrapunham a ideia de que não havia preconceito. Este relato confirma o que fala o autor Junqueira (2013), que há o respeito, entretanto, a discriminação ocorre sutilmente.

Conforme Tomaz Tadeu da Silva (1999), a diferença é um processo linguístico e é discursivamente produzida. Além disso, o autor diz que as relações de poder fazem com "que o 'diferente' seja avaliado negativamente relativamente ao "não diferente"'.

Dinis (2011) afirma que o termo homofobia, que a princípio eramasculinizante e posteriormente passou também a referenciar as outras formas de discriminação contra a diversidade sexual de mulheres lésbicas, mulheres e homens bissexuais, travestis e transexuais, demonstra mais uma das barreiras da língua portuguesa e dos preconceitos implícitos nela, a linguagem é um elemento que exclui e que de permite a expressar preconceitos, isso sobretudo nas línguas de origem latinas, nas quais a concordância com as regras tradicionais e "neutras" da linguagem faz com que sejam utilizados termos masculinos quando referentes a mulheres e homens.

Quanto à homofobia na escola, ela se manifesta por meio de agressões verbais e/ou físicas a que estão sujeitos/as adolescentes que contrastam e não se adequam na sociedade dita heteronormativa, que torna os discursos homossexuais como desviantes. No contexto da sala de aula, usa-se também o termo bullying homofóbico para nomear, especificamente, a violência sofrida por alunos/as com orientações sexuais diferentes daquela considerada dentro da norma. (DINIS, 2011).

Os/as adolescentes participantes dessa pesquisa demonstraram estar parcialmente dentro do que aponta Dinis (2011), pois apresentaram repulsa e comentários homofóbicos, mas disseram não haver agressões físicas.

Louro (1999), em seus estudos, relata que

A escola é, sem dúvida, um dos espaços mais difíceis para que alguém "assuma" sua condição de homossexual ou bissexual. Com a suposição de que só pode haver um tipo de desejo sexual e que esse tipo - inato a todos - deve ter como alvo um indivíduo do sexo oposto, a escola nega e ignora a homossexualidade 
(provavelmente nega porque ignora) e, desta forma, oferece poucas oportunidades para que adolescentes ou adultos assumam, sem culpa ou vergonha, seus desejos. $\mathrm{O}$ lugar do conhecimento mantém-se, com relação à sexualidade, o lugar do desconhecimento e da ignorância. (LOURO, 1999, p. 30)

Percebe-se que a dificuldade em assumir a homossexualidade, a que Louro se refere, a falta de espaço na escola, a negação dos/as professores/as e funcionários/as, tem como consequência a homofobia, a não aceitação, o não respeito e o não entendimento da diversidade sexual.

O relacionamento entre homem e outro homem ou mulher e outra mulher foi visto como fora da norma, causando repulsa e estranhamento. Identificando assim, que a instituição escolar deve atacar tal discurso, com novas aprendizagens a respeito da diversidade sexual.

\section{CONSIDERAÇÕES FINAIS}

A construção de projetos para o futuro integra a vida de todos/as os/as seres, englobando aspectos individuais, sociais, educacionais, econômicos, psíquicos e culturais impregnados de historicidade, práticas, atitudes e simbolizações.

O primeiro ponto a destacar é que a maioria dos/as adolescentes participantes consideravam o casamento como o principal plano de futuro na dimensão sócio afetiva, tanto no Brasil, como em Portugal. Além disso, a ideia de casamento veio acompanhada de filhos/as.

A pesquisa apontou também as diferenças que permeiam diversos comportamentos dos meninos e das meninas em ambos os países. Foi possível notar, através das narrativas analisadas, que determinadas condutas eram admissíveis para garotos e inadmissíveis para garotas, em Portugal e no Brasil, o que mostra que os/as jovens, em muitos aspectos, têm comportamentos e maneiras de pensar que extrapolam a cultura local, mas se fixam na cultura global, ainda machista no mundo, tanto ocidental como oriental. Ela ainda guia os pensamentos dos jovens e norteia maneiras de construírem-se, atuarem e de comportarem-se. Entre elas, andar com preservativo na carteira, ter diversos relacionamentos, ter mais de um parceiro sexual, ter relações sexuais por desejo, o rapaz/homem visto como sexo forte, que tem poder sobre a rapariga/mulher, que precisa "protegê-la". 
O projeto de futuro na dimensão sócio afetiva é ainda muito limitador quando o assunto diz respeito às relações de gênero nos dois países. Esse estudo demonstra que os/as adolescentes insistem nas relações de poder, seja na opressão das mulheres ou dos/as homossexuais. Mesmo Portugal, com avanços significativos nas políticas públicas de educação sexual na escola, ser obrigatória desde 2009, ainda tem o machismo muito enraizado, permeando a vida dos rapazes do país, via a família e sociedade.

Já no Brasil, houve avanços, mas as famílias educam seus/as filhos/as pautadas na cultura heterossexual e machista. A mídia é uma explosão diária de modos de exclusão; de "brincadeiras" de mal gosto contra as minorias; de músicas que colocam a mulher, a jovem, a menina, em um lugar de submissão, de rebaixamento na sociedade; alimentando o universo infantil, juvenil e dos adultos diariamente. As políticas públicas de educação ainda são pontuais, no que tange ao trabalho de educação para minimizar esses machismos, violência, caminhamos vagarosamente nessa vertente.

Em relação à sexualidade, os/as adolescentes, tanto no Brasil, como em Portugal, começaram a desmitificar alguns assuntos que até há bem pouco tempo, eram proibidos ou velados de serem problematizados por eles, como a temática do aborto, da homossexualidade e o uso de preservativos.

A pesquisa em alguns momentos se ateve fortemente, aos discursos e as reflexões possibilitadas pelo grupo focal, sendo que, os/as adolescentes começaram a desmistificar essas temáticas, mas ainda presos à "tradição" passada pela família e sociedade. Nos dois países, esses posicionamentos contraditórios sempre eram colocados e mostrava o quanto o discurso familiar era forte na vida deles e delas, o que nos mostra que eles/as não buscavam a autonomia de conhecimento e que a escola pouco faz esse papel, destoar da família, apresentar outros conhecimentos, fazê-los/as repensar os papéis, as maneiras de atuar, as maneiras de olhar e se relacionar com o outro e com o seu corpo. O que nos mostra o quanto a educação precisa também chegar às famílias, para que eles possam quebrar a barreira do preconceito, machismo e exclusão, para dialogar diferentemente com seus/suas filhos/as.

O estudo traz apontamentos importantes, discursos que nos fazem pensar em maneiras de romper esse vício do machismo, do preconceito e da exclusão. Uma das maneiras deve ser a escola, claro que ela não é a única, mas ela abre caminhos, quando traz a temática de projeto de futuro na dimensão sócio afetiva, mas não só. A escola poderá e terá elementos se os buscar, fazer pensar, envolver, tirar do lugar, movimentar, corpos e mentes, que refletirão nas suas e nas futuras famílias e na sociedade. 
PROJETO DE FUTURO NA DIMENSÃO SÓCIO AFETIVA: COMO SE CONSTROEM AS PERCEPÇÕES DE ALUNOS/AS DO ENSINO SECUNDÁRIO EM PORTUGAL E DO ENSINO MÉDIO NO BRASIL

Vale enfatizar, por fim, que Portugal tem uma lei que possibilita a discussão destes planos de futuro relacionados com a sexualidade. E que a reflexão sobre o tema, é uma temática social importante que deve ocorrer por meio de um trabalho durante toda a vida, começando pela família e por todo o percurso escolar, para que os/as adolescentes possam ressignificar, de maneira criteriosa e autônoma as questões com as quais se deparam durante toda sua vida. As políticas públicas de educação são importantes instrumentos para que elas possam ocorrer na escola e assim se multiplicar em todas as comunidades.

A escola é o local adequado para tratar assuntos como os de projetos de futuro na dimensão sócio afetiva, que envolve a sexualidade e as relações de gênero, pois, é um espaço onde a prática do pensamento crítico e debates para essa formação devem e podem acontecer. Cabe aos/as professores/as terem essa premissa quando chegam à escola, por meio de uma formação inicial e sempre continuada, que atribua aos projetos de futuro, uma valoração importante para o desenvolvimento e novos conhecimentos dos jovens. Uma vez que a escola é um local permeado pela diversidade, deve-se priorizar o convívio respeitoso e democrático. Para tal, atuar pensando no futuro é fundamental, para novas entradas futuras de jovens na escola, por que os que sairão dela, já terão essa garantia de projetos de futuros constituídos em seus planos de vida, formarão famílias homoafetivas ou heteroafetivas, com outros procedimentos, outras maneiras de pensar, fazer, atuar na e pela diversidade.

Portanto, a pesquisa revelou que ao escutar esses/as jovens nos grupos focais, fica evidente que é essencial a problematização da sexualidade, das relações de gênero e da diversidade sexual a partir de questões éticas e sociais que permitam que os/as adolescentes reflitam sobre seus relacionamentos entre pares, com a família, na comunidade, com responsabilidade, respeito, dignidade, criticidade, pensando sempre as diferenças, por que eles se veem como diferentes, e isso em todas as áreas em seus projetos de futuro. E a educação escolar é parte fundamental nesse processo de mudança social.

\section{FUTURO EN DIMENSIÓN SOCIO DEL PROYECTO AFECTIVO: CÓMO CONSTRUIR LA PERCEPCIÓN DE ALUMNOS DE EDUCACIÓN SECUNDARIA EN PORTUGAL Y EN BRASIL}

\section{Resume}


ARAUJO, M. F.; ROSSI, C. R.; TEIXEIRA, M. F. R.; RIBEIRO, P. R. C.

Esta investigación tuvo como objetivo comprender cómo el "proyecto de futuro" con respecto a la dimensión socio-afectiva es construido por estudiantes de preparatoria en Portugal y en Brasil. El proyecto se basa en el concepto de la cultura y la adolescencia como una construcción cultural. La definición de un futuro proyecto fue adoptado en la dimensión mencionada se caracteriza por la definición de los afectos y pasiones. A través de grupos focales con adolescentes fue posible analizar sus relatos sobre el futuro proyecto sobre la dimensión socio-afectiva; para conocer los discursos producidos por ellos sobre cuestiones relativas a la sexualidad, el género y la diversidad sexual y. La encuesta encontró que la mayoría de los adolescentes tenían proyectos para su futuro. Por otra parte, señaló las diferencias que atraviesan varios niños y niñas comportamientos. Se concluyó que el cuestionamiento de estos temas desde las cuestiones éticas que permiten a los adolescentes a reflexionar sobre sus relaciones entre pares, en la comunidad, con la familia, la responsabilidad y la criticidad es esencial. Y la educación es fundamental para este proceso.

Palabras clave: Proyecto de Futuro; Adolescentes; Sexualidad; Las Relaciones de Género; Diversidad Sexual

\title{
PROJECT FUTURE IN SOCIO AFFECTIVE DIMENSION: HOW TO BUILD THE PERCEPTIONS OF STUDENTS SECONDARY EDUCATION IN PORTUGAL AND HIGH SCHOOL IN BRAZIL
}

\begin{abstract}
This research aimed to understand how the "future project" regarding the socio-affective dimension is built by high school students in Portugal and in Brazil. The project was based on the concept of culture and adolescence as a cultural construction. The definition of future project was adopted in the above mentioned dimension characterized by defining affections and passions. Through focus groups with adolescents it was possible to analyze their narratives about the future project on the socio-affective dimension; to get to know the speeches produced by them on issues regarding sexuality, gender and and sexual diversity. The survey found out that most adolescents had projects for their future. Moreover, it pointed out the differences that permeate several boys' and girls' behaviors. It was concluded that the questioning of these issues from ethical questions that allow teenagers to reflect on their
\end{abstract}


PROJETO DE FUTURO NA DIMENSÃO SÓCIO AFETIVA: COMO SE CONSTROEM AS PERCEPÇÕES DE ALUNOS/AS DO ENSINO SECUNDÁRIO EM PORTUGAL E DO ENSINO MÉDIO NO BRASIL

relationships among peers, in the community, with family, responsibility and criticality is essential. And education is central to this process.

Keywords: Future Project; Adolescents; Sexuality; Gender Relations; Sexual Diversity

\section{REFERÊNCIAS:}

AVILA, Sueli de Fatima Ourique de. A adolescência como ideal social.. In: Simposio Internacional Do Adolescente, 2. São Paulo, 2005.

AMARAL, A.; DOMINGUES, J. V.; SILVA, M. R. S.; Escola, Juventude e Corpos Modificados. In: Corpos, Gêneros e Sexualidades: questões possíveis para o currículo escolar. Organizadoras: RIBEIRO, P. R. C.; QUADRADO, R.; $3^{\text {a }}$ edição. Rio Grande: Editora da FURG, 2013

BAUMAN, Zygmunt. O mal-estar na pós-modernidade. Rio de Janeiro: Zahar. 1998

BRITZMAN, Deborah. O que é esta coisa chamada amor: identidade homossexual, Educação e currículo. Rev. Educação \& Realidade, Porto Alegre, v. 21, n. 1, p. 71-96, 1996.

BRITZMAN, Deborag. Curiosidade, sexualidade e currículo. In: O Corpo Educado. Org: LOURO, G. L. $2^{a}$ edição, Belo Horizonte: Autêntica, p. 35-82. 2001.

CAREGNATO, R. C. A.; MUTTI, R. Pesquisa qualitativa: análise de discurso versus análise de conteúdo. Rev. Texto contexto - enferm. [online]., vol.15, n.4, pp. 679-684, 2006.

CUNHA, Maria Isabel. Conta-me agora!:as narrativas como alternativas pedagógicas na pesquisa e no ensino. Rev. Fac. Educ. [online]., vol.23, n.1-2. 1997.

DINIS, Nilson. Fernandes. Homofobia e educação: quando a omissão também é signo de violência. Educar em Revista, Curitiba. N. 39, p. 39-50, 2011

GATTI, Bernadete Angelina; Grupo focal na pesquisa em Ciências Sociais e Humanas. Brasília: Líber Livro, 2005.

HALL, Stuart. A centralidade da cultura: notas sobre as revoluções culturais do nosso tempo. Educação \& Realidade, v. 22, nº 2, jul./dez, 1997

HALL, Stuart. Quem precisa de identidade?. In: SILVA, Tomaz (Org.). Identidade e diferença: a perspectiva dos Estudos Culturais. 15ª edição, Petrópolis, RJ: Vozes, 2014. 
JUSTO, J. S.; O "ficar" na adolescência e paradigmas de relacionamento amoroso da contemporaneidade. Rev. Dep. Psicol.,UFF [online]. 2005, vol.17, n.1, pp. 61-77. 2005.

JUNQUEIRA, Rogério Diniz. Escola e Enfrentamento à Homofobia: pelo reconhecimento da diversidade sexual como fator de melhoria da educação de tod@s. In: Corpos, Gêneros e Sexualidades: questões possíveis para o currículo escolas. Organizador por: RIBEIRO, P. R. C. e QUADRADO, R. P. ; $3^{\mathrm{a}}$ edição. Rio Grande: Editora da FURG, p. 49 - 60. 2013.

LARROSA, Jorge; Tecnologias do eu e educação. In: SILVA, Tomaz. O sujeito da educação: estudos foucaultianos. Petrópolis: Vozes, 2002.

LONGARAY, Deise Azevedo. "Eu já beijei um menino e não gostei, aí beijei uma menina e me senti bem": um estudo das narrativas de adolescentes sobre homofobia, diversidade sexual e de gênero. Dissertação (mestrado) - Universidade Federal do Rio Grande, Programa de Pós-Graduação em Educação em Ciências: Química da Vida e Saúde, RS, 2010.

LOURO, Guacira Lopes. Pedagogias da sexualidade. In: LOURO, G. L. (Org.). O corpo educado - pedagogias da sexualidade. Belo Horizonte: Autêntica, 1999. Vozes. 2003.

Gênero, sexualidade e educação: uma perspectiva pós-estruturalista. 5. ed. Petrópolis, . Gênero e Sexualidade, Pedagogias Contemporâneas. Rev. Pro-Posições, v. 19, n. 2 (56) - maio/ago. 2008.

MAGALHÃES, J.C.; SILVA; F. F.; Descolad@s, divertid@s, atrevid@s, e diferentes: discutindo representações de gênero. In: Corpos, Gêneros e Sexualidades: questões possíveis para o currículo escolas. Organizador por: RIBEIRO, P. R. C. e QUADRADO, R. P. ; $3^{\mathrm{a}}$ edição. Rio Grande: Editora da FURG, p. 30 - 34. 2013.

MARCELINO, M. Q. dos S.; CATAO, M. de F. F. M.; LIMA, C. M. P. de. Representações sociais do projeto de vida entre adolescentes no ensino médio. Rev. Psicol. cienc.prof. [online].vol.29, n.3, pp. 544-557. 2009.

MEYER, Dagmar. Escola, currículo e diferença: implicações para a docência. In: Barbosa, $R$. L. L. Formação de educadores: desafios e perspectivas. São Paulo, UNESP, pp. 257265.2003 .

QUADRADO, Raquel Pereira. Adolescentes: corpos inscritos pelo gênero e pela cultura de consumo. Dissertação (Mestrado). - Fundação Universidade Federal do Rio Grande. Programa de Pós-Graduação em Educação Ambiental, 2006.

RESSEL, L. B.; GUALDA, D. M. R. A sexualidade como uma construção cultural: reflexões sobre preconceitos e mitos inerentes a um grupo de mulheres rurais. Rev. esc. enferm. USP [online], vol.37, n.3, pp. 82-87. 2003. 
PROJETO DE FUTURO NA DIMENSÃO SÓCIO AFETIVA: COMO SE CONSTROEM AS PERCEPÇÕES DE ALUNOS/AS DO ENSINO SECUNDÁRIO EM PORTUGAL E DO ENSINO MÉDIO NO BRASIL

RIBEIRO, Paula Regina Costa; Inscrevendo a sexualidade: discursos e práticas de professoras das séries iniciais do Ensino Fundamental. Tese (Doutorado no Instituto de Ciências Básicas da Saúde). Universidade Federal do Rio Grande do Sul, Porto Alegre. 2002.

RIBEIRO, P. R. C.; SOARES, G. F.; As identidades de gênero. In: Corpos, Gêneros e Sexualidades: questões possíveis para o currículo pedagógico. Organizadora: RIBEIRO, P. R. C.; $3^{\text {a }}$ edição. Rio Grande: Editora da FURG, 2013.

SCOTT, Joan W. "Gênero: Uma Categoria Útil para a Análise Histórica." Traduzido pela SOS: Corpo e Cidadania. Recife, 1990.

SILVA, Tomás Tadeu da. Documentos de identidade: uma introdução às teorias do currículo. Belo Horizonte: Autêntica. $3^{\mathrm{a}}$ edição, 156 p. 1999.

VIANNA, C. P.; UNBEHAUM, S. O gênero nas políticas públicas de educação noBrasil: 1988-2002. Cad. Pesqui.., vol.34, n.121, pp. 77-104. 2004.

WOODWARD, Kathryn. Identidade e Diferença: uma introdução teórica e conceitual. In: SILVA, Tomaz (Org.). Identidade e diferença: a perspectiva dos Estudos Culturais. 15 edição, Petrópolis, RJ: Vozes, 2014.

Data de recebimento: $31 / 01 / 2016$

Data de aceite: 01/03/2016 